\title{
Changes in Calcium Responsiveness and Handling during Keratinocyte Differentiation \\ Potential Role of the Calcium Receptor
}

Daniel D. Bikle, Anita Ratnam, Theodora Mauro, Jon Harris, and Sreekumar Pillai

Departments of Medicine and Dermatology, University of California, and Veterans Administration Medical Center, San Francisco, California 94121

\begin{abstract}
Extracellular calcium concentrations (Cao) $>0.1 \mathrm{mM}$ are required for the differentiation of normal human keratinocytes in culture. Increments in Cao result in acute and sustained increases in the intracellular calcium level (Cai), postulated to involve both a release of calcium from intracellular stores and a subsequent increase in calcium influx through nonspecific cation channels. The sustained rise in Cai appears to be necessary for keratinocyte differentiation. To understand the mechanism by which keratinocytes respond to Cao, we measured the acute effects of Cao on Cai and calcium influx in keratinocytes at various stages of differentiation. We then demonstrated the existence of the calcium receptor $(\mathrm{CaR})$ in keratinocytes and determined the effect of calcium-induced differentiation on its mRNA levels. Finally, we examined the role of Cai in regulating both the initial rise in Cai after the switch to higher Cao and the activity of the nonspecific cation channel through which calcium influx occurs. Our data indicate that the acute Cai response to Cao is lost as the cells differentiate and increase their basal Cai. These data correlated with the decrease in CaR mRNA levels in cells grown in low calcium. However, calcium influx as measured by ${ }^{45} \mathrm{Ca}$ uptake increased with differentiation in $1.2 \mathrm{mM}$ calcium, consistent with the increase in CaR mRNA in these cells as well as the calciuminduced opening of the nonspecific cation channels. We conclude that the keratinocyte contains a $\mathrm{CaR}$ that regulates both the initial release of Cai from intracellular stores and the subsequent increase in calcium flux through nonspecific calcium channels. A rising level of Cai may turn off the release of calcium from intracellular stores while potentiating the influx through the nonspecific cation channels. Differentiation of keratinocytes appears to increase the $\mathrm{CaR}$, which may facilitate the maintenance of the high Cai required for differentiation. (J. Clin. Invest. 1996. 97:10851093.) Key words: calcium receptor • keratinocytes • cation channel $\bullet$ calcium influx $\bullet$ intracellular free calcium
\end{abstract}

Address correspondence to Daniel D. Bikle, M.D., Ph.D., VA Medical Center, Endocrine Unit (111), 4150 Clement Street, San Francisco, CA 94121. Phone: 415-750-2089; FAX: 415-750-6929.

Received for publication 10 February 1995 and accepted in revised form 27 November 1995.

J. Clin. Invest.

(C) The American Society for Clinical Investigation, Inc.

0021-9738/96/02/1085/09 \$2.00

Volume 97, Number 4, February 1996, 1085-1093

\section{Introduction}

Normal human keratinocytes grow and differentiate in vitro, forming stratified sheets that retain the basic organization of the intact skin $(1,2)$. Extracellular calcium concentrations $(\mathrm{Cao})^{1}>0.1 \mathrm{mM}$ initiate a cascade of genomic and nongenomic events in which keratinocytes progress from small proliferating cells in monolayers to stratified sheets with cornified envelopes (CE) (3-5). A key feature in this response to Cao is the rise in intracellular calcium (Cai) (6-9). Keratinocytes are unusual in their ability to respond to relatively small changes in Cao. For example, a sustained increase in Cai is observed in normal murine keratinocytes when their Cao was changed from 0.1 to $0.12 \mathrm{mM}$, whereas fibroblasts cannot distinguish such small changes (10). The concentrations of Cao (0.1-0.16 $\mathrm{mM})$ that control the optimal expression of specific differentiation-related mouse keratinocyte genes correspond to the same concentrations of Cao that elicit the Cai response (11). At concentrations that block membrane calcium flux in a variety of cells including keratinocytes, lanthanum blocks the ability of Cao to increase Cai and prevents calcium-induced keratinocyte differentiation (12). These findings support the concept that the rise in Cai after an increase in Cao is critical for the regulation of keratinocyte differentiation and that this rise in Cai is itself tightly regulated.

The means by which Cao increases Cai is likely to involve several processes. Cao activates the phospholipase C (PLC) pathway resulting in a rise in inositol trisphosphate $\left(\mathrm{IP}_{3}\right)$ that coincides with the increase in Cai (13-17). $\mathrm{IP}_{3}$ could either be the mediator of the rise in Cai by releasing calcium from intracellular stores or the result of calcium-activated PLC activity. Cao also stimulates transmembrane calcium flux (18). This appears to occur by calcium activation of both chloride channels, leading to hyperpolarization of the membrane (19) and voltageindependent nonspecific cation channels permeable to calcium (20). The net result is that Cao leads to an acute but transient rise in Cai followed by a sustained increase in Cai, which appears to be necessary for the differentiation response $(6-12,21-23)$.

These features of the Cai response of the keratinocyte to Cao are reminiscent of the Cai response of the parathyroid gland to Cao, where coupling of changes in Cao to the activation of the PLC pathway and activation of voltage-independent calcium influx $(24,25)$ are now known to be mediated by a calcium receptor (CaR) (26). This receptor, when expressed

1. Abbreviations used in this paper: $\mathrm{AM}$, acetoxymethylester; Cai, intracellular free $\mathrm{Ca}$ concentration; Cao, extracellular Ca concentration; $\mathrm{CaR}$, Ca receptor; $\mathrm{CE}$, cornified envelope; $\mathrm{IP}_{3}$, inositol trisphosphate; KGM, keratinocyte growth medium; PLC, phospholipase C; RT, reverse transcriptase; TES, $N$-tris (hydroxymethyl) methyl-2aminoethane sulfonic acid. 
in oocytes, mediates calcium (and other cation)-stimulated increases in Cai, $\mathrm{IP}_{3}$, and $\mathrm{Cl}^{-}$currents across the membrane (26). In this report we provide evidence for the existence of the same receptor in keratinocytes.

In our own studies and those of others, the Cai response to Cao appears to change with differentiation. The acute rise in Cai in response to increased $\mathrm{CaO}$ is greater in undifferentiated normal keratinocytes and in transformed keratinocytes that fail to differentiate $(6,9,21)$ than in differentiated keratinocytes. However, the basal Cai levels increase with differentiation $(7,21)$, and, as shown in this study, this is due in part to a rise in calcium influx with differentiation. Therefore, to determine the mechanism underlying the differentiation-dependent change in the Cai response to Cao, we analyzed the change in the acute response of Cai to $\mathrm{Cao}$, the change in calcium influx, and the change in mRNA levels of the $\mathrm{CaR}$ as the keratinocytes differentiate in response to calcium.

\section{Methods}

Materials. Indo-1 acetoxymethylester (AM) and Fura-2 AM were purchased from Molecular Probes, Inc. (Eugene, OR). Ionomycin was from Calbiochem Corp. (San Diego, CA). All other chemicals were from Sigma Chemical Company (St. Louis, MO).

Cell culture. First- or second-passage keratinocytes isolated from neonatal human foreskins were used in these studies. They were grown in serum-free keratinocyte growth medium (KGM) obtained from Clonetics Corp. (San Diego, CA) or from GIBCO BRL (Gaithersburg, MD) as described previously (27). Briefly, keratinocytes were isolated from newborn human foreskins using $0.1 \%$ trypsin/ $0.01 \%$ EDTA, and the primary cultures were grown to $80-90 \%$ confluence in KGM containing $0.07 \mathrm{mM}$ calcium. Second-passage keratinocytes were then grown in KGM containing variable concentrations of calcium and were evaluated at different stages of confluence as indicated. For electrophysiologic studies, the cells were studied $1 \mathrm{~d}$ after replating.

Measurement of Cai. Cai measurement in suspended keratinocytes was carried out as described previously $(7,21,23)$. Briefly, trypsinized keratinocytes were loaded with $2 \mu \mathrm{M}$ Indo- $1 \mathrm{AM}$ in buffer A $(20 \mathrm{mM}$ Hepes buffer, $\mathrm{pH} 7.4$, containing $120 \mathrm{mM}$ sodium chloride, $5 \mathrm{mM}$ potassium chloride, $1 \mathrm{mM}$ magnesium chloride, $1 \mathrm{mg} / \mathrm{ml}$ pyruvate, $1 \mathrm{mg}$ / $\mathrm{ml}$ glucose, and $0.03 \mathrm{mM}$ calcium chloride). Cells were then washed three times with buffer $\mathrm{A}$ and resuspended in buffer $\mathrm{A}$ at the original cell concentration of 1-1.5 million cells per milliliter. Cells were washed and resuspended in fresh buffer A before each measurement, and all the measurements were completed within 2-2.5 h after Indo-1 loading. Cells studied in this fashion show little Indo-1 leakage. Fluorescence was recorded with a fluorimeter (650-40; Perkin-Elmer Corp., Norwalk, CT) using $350 \mathrm{~nm}$ and $405 \mathrm{~nm}$ for excitation and emission wavelengths, respectively. Each sample was calibrated by the addition of ionomycin (10 $\mu \mathrm{M}$ final concentration) (Fmax) followed by $0.1 \%$ Triton X-100 and 10 mM EGTA/Tris, pH 8.3 (Fmin). Cai was calculated from the following formula: $\mathrm{Cai}=K_{\mathrm{d}}(\mathrm{F}-\mathrm{Fmin}) /$ $\left(\right.$ Fmax $-\mathrm{F}$ ) where $K_{\mathrm{d}}$ for Indo- 1 for Ca is $250 \mathrm{nM}(28)$.

Cai measurements in attached cells. Cai levels of keratinocytes attached to glass coverslips were measured using two different methodologies. The first used a laser-based fluorescence image analyzer system from Meridian Instruments (Ann Arbor, MI) (23). The cells attached to special coverslips of 1-mm thickness were loaded with $1 \mu \mathrm{M}$ Indo-1 AM and mounted on the stage of an inverted fluorescence microscope. The fluorescence was determined at an excitation wavelength of 351-363 nm, and emitted light was detected simultaneously by two photomultiplier tubes, one set at wavelength maxima for the Ca-Indo-1 complex $(405 \mathrm{~nm})$ and the other set for free Indo-1 $(485 \mathrm{~nm})$. The ratio of 405:485 was used for the Cai calculation. The second method used an inverted Nikon microscope in which the fluorescent signal was detected with a CCD camera (Hamamatsu Phototonics, Bridgewater, $\mathrm{NJ}$ ) and digitally analyzed and stored using the software program Fluor (Universal Imaging, West Chester, PA). This second technique involved loading the cells with $6.25 \mu \mathrm{M}$ Fura-2 AM in $0.1 \%$ Pluronic (Molecular Probes, Inc.) at room temperature for $30 \mathrm{~min}$ followed by a 30-min rinse in KGM Ringer. The keratinocytes were superfused with KGM Ringer containing $0.07 \mathrm{mM} \mathrm{Ca}^{2+}, 2 \mathrm{mM} \mathrm{Sr}^{2+}$, or $2 \mathrm{mM} \mathrm{Ba}{ }^{2+}$, which was gassed with $95: 5 \% \mathrm{O}_{2} / \mathrm{CO}_{2}$. The cells were then alternately illuminated with $200 \mathrm{~ms}$ flashes of 340 and $380 \mathrm{~nm}$ light every $10 \mathrm{~s}$, monitoring the emission wavelength of $510 \mathrm{~nm}$. The use of ratio analysis eliminates artifacts because of cell thickness, differential loading, photodynamic damage, or dye leakage.

Measurement of ${ }^{45} \mathrm{Ca}$ influx in attached cells. To study the influx of calcium, cultures of keratinocytes in 12-well multiwell plates at different stages of confluence were incubated with $1 \mathrm{ml}$ of the Hepes buffer used for Cai measurement (buffer A) containing 0.03 or $1.2 \mathrm{mM}$ calcium and different amounts of ${ }^{45} \mathrm{Ca}$ (keeping the specific activity constant) for various lengths of time (12). The plates were washed three times with $1 \mathrm{mM}$ EGTA solution, cells were dissolved in $0.1 \mathrm{~N}$ $\mathrm{NaOH}$, and an aliquot was counted to quantitate the amount of ${ }^{45} \mathrm{Ca}$ taken up into the cells.

Electrophysiologic measurements. The methods were as described previously $(19,20)$. The standard external solution (KGM buffer) consisted of (in mM): $135 \mathrm{NaCl}, 5 \mathrm{KCl}, 0.07 \mathrm{CaCl}_{2}, 28 \mathrm{~N}$-tris (hydroxymethyl) methyl-2-aminoethane sulfonic acid (TES), $14 \mathrm{NaHCO}_{3}$, $\mathrm{NaOH}$ to adjust the $\mathrm{pH}$ to 7.4, and 10 glucose ( $\mathrm{pH} 7.4,330 \mathrm{mOsm})$. The solution was gassed with a $5: 95 \% \mathrm{CO}_{2} / \mathrm{O}_{2}$ mixture during the experiments. KGM buffer containing $2 \mathrm{mM} \mathrm{Sr}^{2+}$ or $2 \mathrm{mM} \mathrm{Ba}^{2+}$ was added to the bath solution through a port in the perfusion chamber. The pipette contained (in $\mathrm{mM}$ ): $150 \mathrm{~K}$-aspartate, $20 \mathrm{KCl}, 10$ tetramethyl ammonium hydroxide-TES and $50 \mu \mathrm{g} / \mathrm{ml}$ nystatin $(\mathrm{pH} 7.25$, $330 \mathrm{mOsm}$ ). Patch pipettes were pulled from borosilicate glass (Sutter Instruments, Novato, CA) on a puller (Brown-Flaming; Sutter Instruments) to a resistance of $102 \mathrm{Mohm}$. After seal formation, currents were recorded in the excised inside-out nystatin-permeabilized whole-cell configuration (29). Membrane currents were measured with an amplifier (Axopatch 200; Axon Instruments, Inc., Foster City, CA). The current signal was filtered at $1 \mathrm{kHz}$ with an eight-pole lowpass Bessel filter (Frequency Devices, Inc., Haverhill, MA) digitized at $521 \mu \mathrm{s} /$ point using a TI-1 DMA interface connected to a $486 \mathrm{com}$ puter (Everex, Fremont, CA) and stored on disk. Whole-cell and single-channel currents were analyzed using the pClamp program (version 6.0; Axon Instruments, Inc.). For isolation of $\mathrm{Cl}^{-}$currents, linear leak currents and uncompensated currents through membrane capacitance were measured using a P/4 protocol (30). P/4 currents were digitally subtracted from the current record for analysis of voltage-gated currents.

CaR $m$ RNA levels. Total RNA was extracted by the method of Chomczynski and Sacchi (31). In brief, the cells were dispersed in lysis solution (4 M guanidinium thiocyanate, $25 \mathrm{mM}$ sodium citrate, $0.5 \%$ sarcosyl, $0.1 \mathrm{M}$ 2-mercaptoethanol), RNA was purified after a series of phenol/chloroform extractions and after ethanol precipitation was quantitated by spectroscopy. The quality of the RNA was assessed by $1 \%$ agarose-formaldehyde electrophoresis. Two methods of quantifying the mRNA levels for the CaR were used. The first method used reverse transcriptase (RT)-PCR. 5- $\mu$ g RNA samples were reverse transcribed with recombinant M-MuLV RT (Boehringer Mannheim Corp., Indianapolis, IN) and amplified by standard PCR procedures. Samples were assessed for GAPDH using the primers CGGCCATCACGCCACAGTTT and TCACCACCATGGAGAAGGCT, and for the CaR using the primers TTCCGCAACACACCCATTGTCAAGG and GGATCCCGTGGAGCCTCCAAGGCTG (32). The GAPDH primers result in a 293-bp fragment, whereas the $\mathrm{CaR}$ primers encode a 823-bp fragment. Preliminary experiments showed that 22 cycles of PCR were within the linear portion of cDNA production from the GAPDH message, whereas 32 cycles were within the linear portion of cDNA production from the $\mathrm{CaR}$ message. 

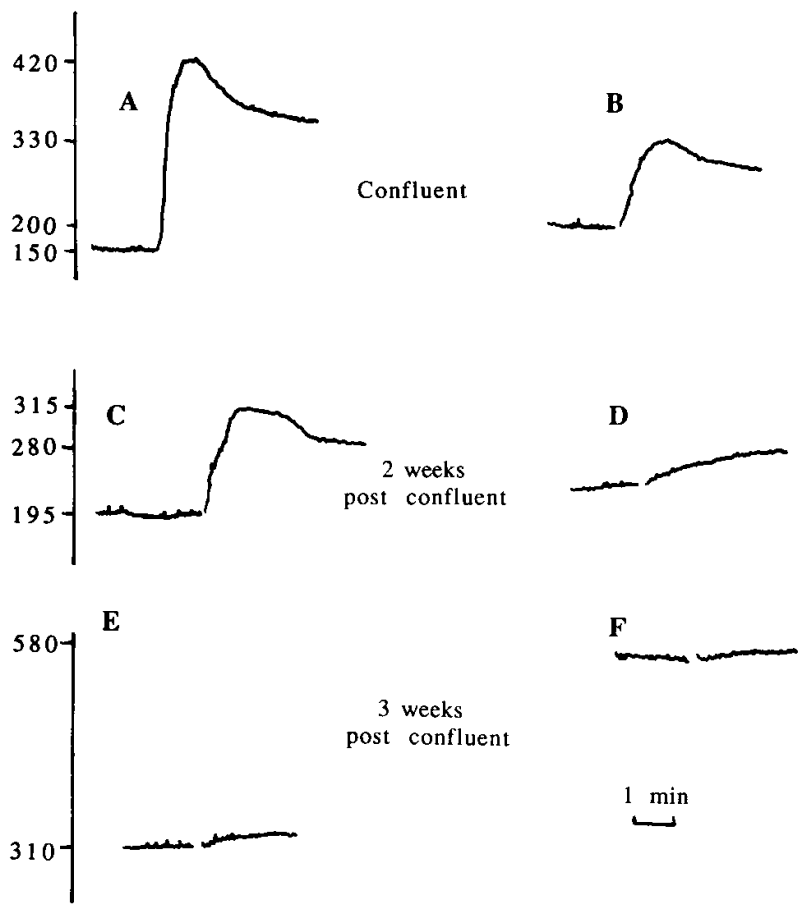

3 weeks post confluent

Figure 1. The ability of Cao to increase Cai in keratinocytes grown in 0.15 or $1.2 \mathrm{mM}$ Cao and studied at $100 \%$ confluence $(7 \mathrm{~d})(A, B), 2 \mathrm{wk}$ after confluence $(C, D)$, or 3 wk after confluence $(E, F)$. Cai was measured in trypsinized cells in suspension. Baseline measurements in all cases were performed in cells suspended in $0.03 \mathrm{mM}$ Cao to which $2 \mathrm{mM}$ Cao (final) was then added. Cells grown in $0.15 \mathrm{mM}$ Cao to confluence had the greatest response to Cao. With time in culture, this response was lost, and it was lost faster in cells grown in $1.2 \mathrm{mM}$ Cao. Similar results were seen when cells grown in $0.07 \mathrm{mM}$ Cao were compared with those grown in $1.2 \mathrm{mM}$ Cao.

Accordingly, each sample underwent 22 cycles with the GAPDH primers and 32 cycles with the CaR primers. In all cases, controls containing either no sample or no RT were performed to exclude DNA contamination in the tubes or in the samples. In previous experiments we found that expression of the GAPDH gene does not change with calcium-induced differentiation, and we have used the levels of the GAPDH mRNA determined by RT-PCR to normalize the data for the CaR mRNA. The second method used ribonuclease protection as previously described (33). The 823-bp PCR product was subcloned into pGEM4Z (Promega, Madison, WI). This construct was linearized using Sph1, from which radiolabeled RNA was produced, starting at the SP6 promoter using the riboprobe kit (Promega). The riboprobe was gel purified before use. $30 \mu \mathrm{g}$ RNA was incubated with $2-4 \times$ $10^{5} \mathrm{cpm}$ of the riboprobe overnight at $45^{\circ} \mathrm{C}$ before RNase digestion and separation of the products on a sequencing gel. Quantitation was performed by autoradiography and densitometry. This probe protects a 298-bp fragment predicted by the presence of the Sph1 site within the 823-bp fragment.

Sequencing the 823-bp fragment. The 823-bp fragment subcloned into pGEM4Z was sequenced in both directions starting with the SP6 and T7 sites flanking the insert. Sequencing was performed using the Sequenase kit (version 2; U.S. Biochemical Corp., Cleveland, OH). Primers were prepared by the Biomolecular Resource Center (University of California, San Francisco, CA). Sequence analysis and alignments were performed on-line using selected programs in IntelliGenetics, Inc. (Mountain View, CA).

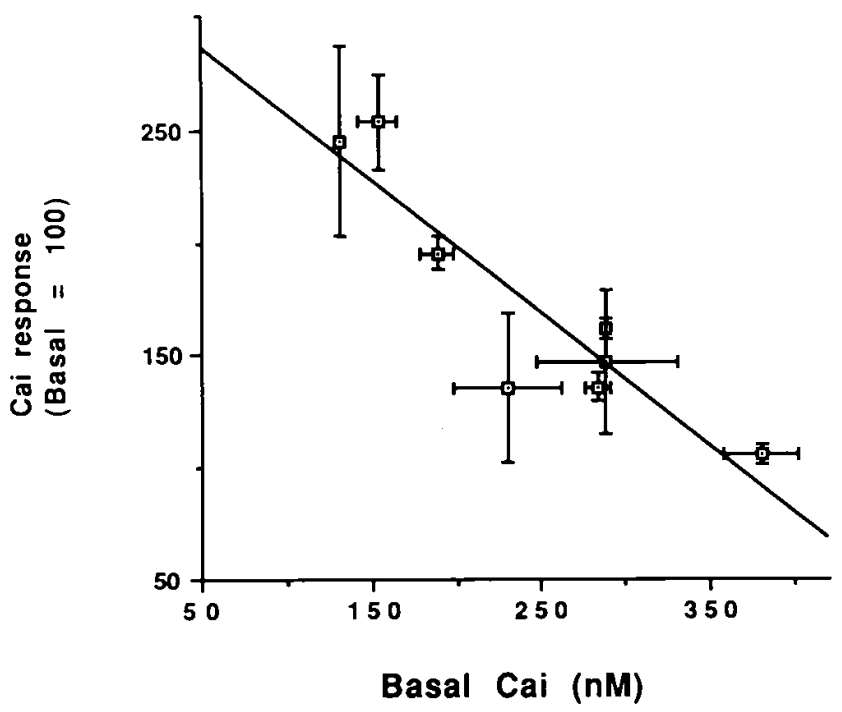

Figure 2. The relationship between basal Cai to Cao induced Cai increases. Data from three separate experiments as represented by Fig. 1 were plotted to show the peak Cai response to the acute addition of $2 \mathrm{mM}$ Cao as a function of the basal Cai. An inverse relationship was found, suggesting that undifferentiated keratinocytes having low basal Cai respond most to Cao, and differentiated cells having high basal Cai respond least to Cao. Data are expressed as mean \pm SD of three determinations for each point.

\section{Results}

To determine the influence of differentiation on the ability of the keratinocytes to respond to Cao, we grew keratinocytes in $1.2 \mathrm{mM}$ Cao to permit differentiation or $0.07-0.15 \mathrm{mM}$ Cao to retard differentiation and quantitated the Cai response to Cao at different stages of confluence. At the time of assay the medium was changed to calcium free, cells were loaded with Indo-1, and the basal fluorescence was measured. The response of cells to $2.0 \mathrm{mM}$ Cao was then measured under identical conditions in all the cell preparations. As seen in Fig. 1, the response of keratinocytes to Cao varied as the cells differentiated. Keratinocytes grown in low calcium to confluence had a much greater increase in Cai after the addition of $2 \mathrm{mM}$ Cao than did cells grown in $1.2 \mathrm{mM}$ Cao. Beyond confluence, the calcium response was progressively lost, especially the initial transient increase in Cai, and this loss occurred more rapidly in the cells grown in $1.2 \mathrm{mM} \mathrm{Cao,} \mathrm{corresponding} \mathrm{to} \mathrm{their} \mathrm{faster}$ rate of differentiation. Similar results were obtained in other experiments in which cells grown in $0.07 \mathrm{mM}$ Cao were compared with those grown in $1.2 \mathrm{mM}$ Cao.

The basal Cai followed an inverse relationship to the acute Cai response to Cao (Fig. 2). Less differentiated cells (0.07 $\mathrm{mM}$ Cao, preconfluent) displayed the lowest basal Cai and the greatest Cai response to $2 \mathrm{mM}$ Cao, whereas more differentiated cells (1.2 mM Cao, postconfluent) displayed the highest basal Cai and the lowest Cai response to $2 \mathrm{mM}$ Cao.

When the Cai of individual cells was measured using the ACAS-570 laser-based image analyzer (Meridian Instruments) (Fig. 3), we observed heterogeneity of the response to Cao. In the cells grown to $60 \%$ confluence in $0.07 \mathrm{mM} \mathrm{Cao,} \mathrm{es-}$ sentially all cells responded to $2 \mathrm{mM}$ Cao with an increase in Cao. As the cultures progressed in time, fewer cells responded; 


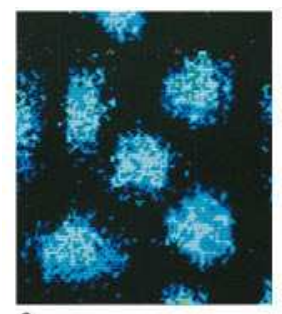

A

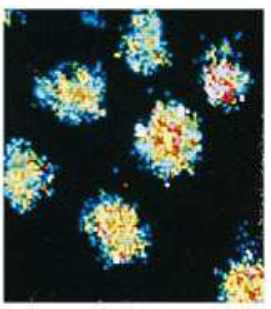

B

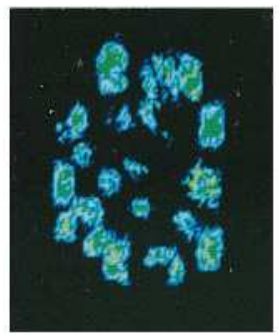

E

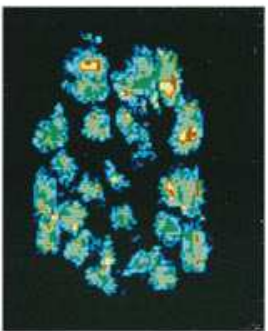

F



I



J

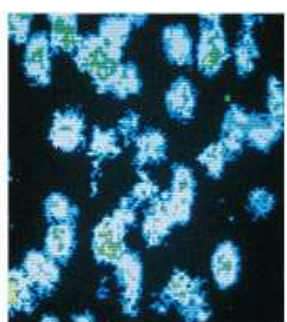

C

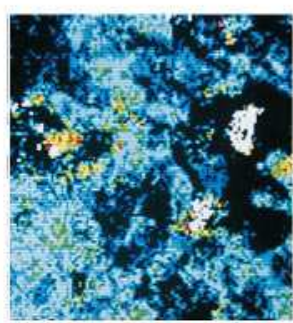

G

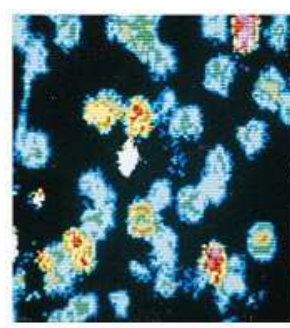

D

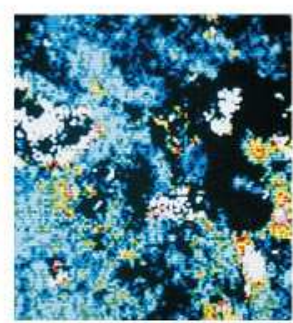

H

Figure 3. Ability of Cao to increase Cai in attached keratinocytes grown in 0.07 and $1.2 \mathrm{mM}$ Cao for 4,7 , and $10 \mathrm{~d}$. Cai was measured using cell imaging as described in Methods. The six panels on the left $(A, B, E, F, I, J)$ are cultures grown in $0.07 \mathrm{mM} \mathrm{Cao} ; A, E$, and $I$ are $4-, 7-$, and $10-\mathrm{d}$ cultures in $0.03 \mathrm{mM} \mathrm{CaO}$ at the time of measurement, respectively, whereas $B, F$, and $J$ are the same cultures 3 min after the addition of $2 \mathrm{mM}$ Cao. The four panels on the right $(C, D, G, H)$ are cultures grown in 1.2 $\mathrm{mM} \mathrm{Cao} ; C$ and $G$ are 4- and 7-d cultures in $0.03 \mathrm{mM}$ Cao, respectively, whereas $D$ and $H$ are the same cultures after the addition of $2 \mathrm{mM}$ Cao. Meaningful data from 10-d cultures grown in $1.2 \mathrm{mM}$ Cao could not be obtained because of stratification. The color scale for Cai quantitation is shown in the lower right. As seen, the results from cell imaging correlate to the results from cell suspensions in that the Cai response to Cao appears to be lost as the cells differentiate.

this decrease in response was more pronounced in the cells grown in $1.2 \mathrm{mM}$ calcium. Thus, attached cells displayed a qualitatively similar response to Cao with differentiation as cells evaluated in suspension, although the extent of response and basal Cai varied between the two systems. Data from these two types of studies indicate a progressive loss of the acute Cai response of keratinocytes to Cao as the cells differentiated.

In previous experiments, we had found that the Cai response to Cao was saturable, with maximum response at $2 \mathrm{mM}$ Cao, suggesting a receptor-mediated mechanism (7). The CaR in the parathyroid gland is activated not only by calcium but by other cations, including barium and strontium $(24,25)$. Using single-cell recordings, we found that nearly $50 \%$ of cells grown to confluence in $0.07 \mathrm{mM}$ calcium showed a robust Cai response to both barium and strontium (Table I). Strontium increased Cai in 7 of 16 cells from 77 to $235 \mathrm{nM}$, whereas barium increased Cai in 7 of 16 cells from 67 to $181 \mathrm{nM}$. Under comparable circumstances, calcium stimulated Cai in nearly all cells (data not shown). Resting Cai was not significantly different in responding and nonresponding keratinocytes.

A second feature of the CaR from parathyroid tissue is its coupling to chloride currents (26). Such currents have been described in keratinocytes (19). To determine whether such currents were linked to a $\mathrm{CaR}$ similar to that found in parathyroid cells, we compared the ability of strontium and barium to activate the chloride current previously shown to be activated by calcium (19). The results of representative recordings are shown in Fig. 4. Although the amplitude of these currents var-
Table I. Cation-stimulated Cai Increments

\begin{tabular}{|c|c|c|c|}
\hline & Condition & $\begin{array}{c}\text { Intracellular } \\
\mathrm{Ca}^{2+}\end{array}$ & $P$ value \\
\hline & & $n m$ & \\
\hline \multicolumn{4}{|l|}{ Response to $\mathrm{Ba}^{2+}$} \\
\hline \multirow[t]{2}{*}{ All cells $(n=16)$} & Control & $72.72 \pm 12.57$ & NS \\
\hline & $2 \mathrm{mM} \mathrm{Ba}^{2+}$ & $122.80 \pm 20.21$ & \\
\hline \multirow[t]{2}{*}{ Cells that responded $(n=7)$} & Control & $66.57 \pm 8.63$ & $<0.01$ \\
\hline & $2 \mathrm{mM} \mathrm{Ba}^{2+}$ & $181.48 \pm 21.80$ & \\
\hline \multirow[t]{2}{*}{ Cells with no response $(n=9)$} & Control & $77.37 \pm 22.10$ & NS \\
\hline & $2 \mathrm{mM} \mathrm{Ba}^{2+}$ & $78.22 \pm 22.54$ & \\
\hline \multicolumn{4}{|l|}{ Response to $\mathrm{Sr}^{2+}$} \\
\hline \multirow[t]{2}{*}{ All cells $(n=16)$} & Control & $72.78 \pm 3.62$ & $<0.05$ \\
\hline & $2 \mathrm{mM} \mathrm{Sr}^{2+}$ & $144.42 \pm 22.46$ & \\
\hline \multirow[t]{2}{*}{ Cells that responded $(n=7)$} & Control & $76.67 \pm 4.83$ & $<0.01$ \\
\hline & $2 \mathrm{mM} \mathrm{Sr}^{2+}$ & $234.75 \pm 16.15$ & \\
\hline \multirow[t]{2}{*}{ Cells with no response $(n=9)$} & Control & $69.76 \pm 5.53$ & NS \\
\hline & $2 \mathrm{mM} \mathrm{Sr}^{2+}$ & $74.20 \pm 8.10$ & \\
\hline
\end{tabular}

32 cells were analyzed for their Cai response to either barium $(n=16)$ or strontium $(n=16)$. Normal human keratinocytes were plated for $1 \mathrm{~d}$ on glass coverslips in KGM medium containing $0.07 \mathrm{mM}$ calcium. After loading the cells with Fura-2, baseline Cai was measured while the cells were superfused with KGM Ringer (see Methods) containing $0.07 \mathrm{mM}$ calcium. The superfusing solution was changed to KGM Ringer without calcium but containing either $2 \mathrm{mM}$ strontium or barium, and the Cai was recorded over the subsequent $30 \mathrm{~min}$. The data are expressed as mean $\mathrm{nM}$ change $\pm \mathrm{SD}$ of all cells and for the responsive and nonresponsive cells. 

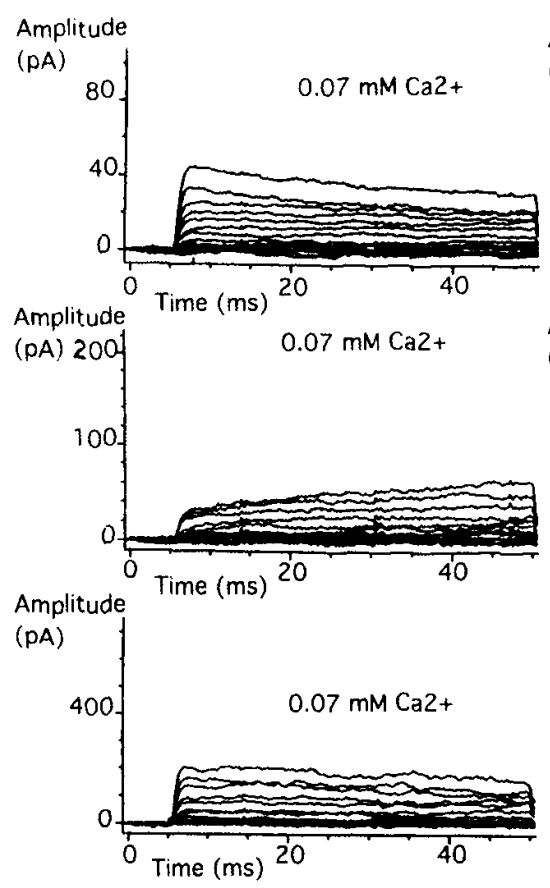
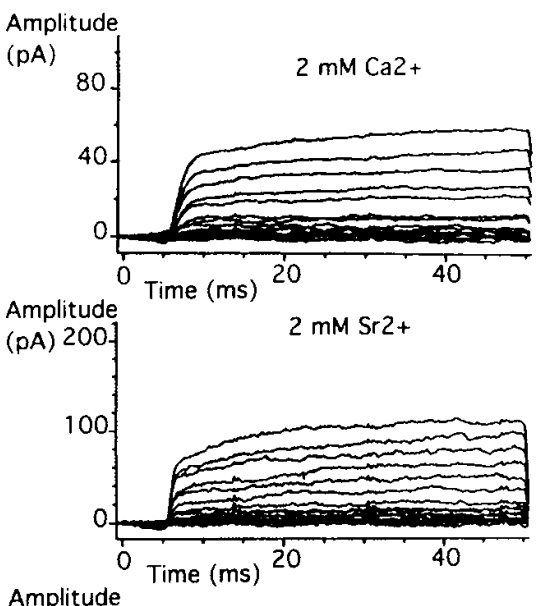

(pA)

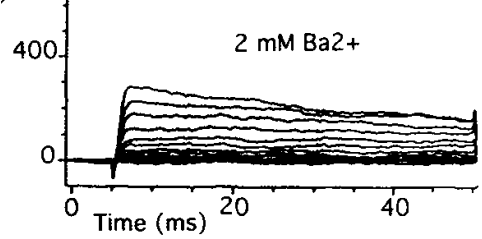

Figure 4. Effect of calcium, barium, and strontium on the calcium-sensitive chloride current. Normal human keratinocytes were plated for $1 \mathrm{~d}$ in plastic 35-mm plates with KGM medium containing $0.07 \mathrm{mM}$ calcium. (Left) Baseline currents in extracellular solution of KGM Ringer containing $0.07 \mathrm{mM}$ calcium. (Right) Currents from the same cells after addition of $2 \mathrm{mM}$ calcium, $2 \mathrm{mM}$ strontium, or $2 \mathrm{mM}$ barium. The cell membrane potential was stepped from the holding potential of $-40 \mathrm{mV}$ to potentials between -80 and $+80 \mathrm{mV}$ in increments of $10 \mathrm{mV}$. Duration of the voltage steps was $50 \mathrm{~ms}$. Differences in current amplitude reflect different cell sizes. These tracings are representative of measurements from 8-10 cells for each cation. ied from cell to cell, $2 \mathrm{mM}$ calcium, strontium, and barium increased the current for any given increment in voltage. Calcium led to an increase in the voltage-sensitive chloride current of $241 \%( \pm 61 \%)$ in all 10 cells studied. Addition of strontium caused an average increase of $50 \%( \pm 13 \%)$ in the voltage-sensitive chloride current in 5 of 10 cells studied. Similarly, barium caused an increase of $38 \%( \pm 12 \%)$ in the voltage-sensitive chloride currents in 3 of 8 cells studied. There was no significant effect of strontium or barium on voltageindependent currents that contain both the large and small nonspecific cation channels. An increase in the chloride current would hyperpolarize the cell and increase the driving force for cation (e.g., calcium) entry.

To test more directly for the presence of a CaR, we examined keratinocytes for the recently described CaR mRNA using RT-PCR and primers developed for human tissue (32). We obtained an 823-bp fragment that was highly homologous to the comparable region of the bovine and human sequences $(26,34)$ (Fig. 5). We found five differences with the human sequence (bases 1926, 2148, 2231, 2393, 2709), none of which resulted in a change in the amino acid residue. In all cases, the keratinocyte sequence was identical to the bovine sequence where it differed from the human sequence, suggesting that these changes may be benign polymorphisms.

To determine whether the mRNA levels of the CaR were affected by calcium-induced differentiation, we grew keratinocytes in 0.03 or $1.2 \mathrm{mM} \mathrm{Cao}$ and evaluated their $\mathrm{CaR}$ mRNA levels at different times. The results are shown in Fig. 6 . The top panel shows the results of one experiment using RT-PCR. The middle panel shows the results of a different experiment using ribonuclease protection assay. The bottom panel combines the results of three separate experiments using RT-PCR. Cells grown in $0.03 \mathrm{mM}$ Cao have less CaR mRNA and tend to lose it with time, compared with cells grown in 1.2 $\mathrm{mM}$ calcium, which show an increase in their CaR mRNA levels with time. This rise in CaR mRNA levels correlated with the rise in Cai, suggesting that the CaR mediated not only the acute increase in Cai best seen in the undifferentiated cells but also the more sustained increase in Cai best seen in the differentiated cells and thought in other cell systems to be mediated by calcium influx through calcium channels.

To determine whether the sustained increase in Cai after increased Cao involved calcium influx, we carried out the ${ }^{45} \mathrm{Ca}$ influx studies shown in Fig. 7, $A-C$. Keratinocytes were grown in 0.07 or $1.2 \mathrm{mM}$ Cao until $80 \%$ confluent (preconfluent), confluent, or $1 \mathrm{wk}$ postconfluent. To determine the time course of ${ }^{45} \mathrm{Ca}$ uptake by these cells, medium was changed to calcium-free conditions $10 \mathrm{~min}$ before assay, and ${ }^{45} \mathrm{Ca}$ was added in $0.03 \mathrm{mM}$ calcium for $1 \mathrm{~h}$, after which the maximum calcium concentration was raised to $1.2 \mathrm{mM}$ without changing the specific activity of ${ }^{45} \mathrm{Ca}$. At different times throughout the assay, the medium was removed, the cells were washed, and the ${ }^{45} \mathrm{Ca}$ content of the cells was determined and normalized to cell number (as assessed by DNA content). Time courses of ${ }^{45} \mathrm{Ca}$ uptake using preconfluent, confluent, and $1 \mathrm{wk}$ postconfluent cells grown in 0.07 and $1.2 \mathrm{mM}$ Cao were determined. When calcium influx was assayed at low Cao $(0.03 \mathrm{mM})$, preconfluent keratinocytes grown in $0.07 \mathrm{mM}$ Cao had a higher peak ${ }^{45} \mathrm{Ca}$ uptake than did preconfluent keratinocytes grown in $1.2 \mathrm{mM}$ Cao. This uptake peaked by $10 \mathrm{~min}$ and decreased thereafter. The ability of cells to accumulate calcium at $0.03 \mathrm{mM}$ Cao decreased in the cells grown in $0.07 \mathrm{mM} \mathrm{Cao}$ but not in the cells grown in $1.2 \mathrm{mM}$ Cao. When calcium uptake was assayed at higher Cao concentrations (1.2 mM Cao), cells grown in $1.2 \mathrm{mM}$ calcium showed a progressive increase in their ability to accumulate calcium as they differentiated. This was not seen in cells grown in $0.07 \mathrm{mM}$ Cao. Thus, it appears that calcium accumulation by keratinocytes at 0.03 and $1.2 \mathrm{mM}$ Cao proceeds by two different mechanisms that are affected differently by calcium-induced differentiation. The loss in uptake of calcium at $0.03 \mathrm{mM}$ Cao is best seen in keratinocytes grown in $0.07 \mathrm{mM}$ Cao and correlates with the loss of the CaR mRNA 
BOV: CGTCAAGGCACCAACCGGGAGCTCTCCTATCTCCTTCTCTTCTCCCTGCTCTGCTGCTTCTCCAGCT 11111111111111111 11111111111 11111 11111111111111111111111111111111 $1111111111111111111111111111111111111111111111111111111\} 11111111$ HUM: TGTCAAGGCCACCAACCGAGAGCTCTCCTACCTCCTCCTCTTCTCCCTGCTCTGCTGCTTCTCCAGCT

BOV: CCCTGTTCTTCATCGGGGAGCCCCAGGACTGGACGTGCCGCCTGCGCCAGCCGGCCTTTGGCATCAGC $1111111111111111111111111111111+111111111111111111111111111111111111$ ER: CCCTGTTCTTCATCGGGGAGCCCCAGGACTGGACGTGCCGCCTGCGCCAGCCGGCCTIGGCATCAGC 1111111111111111111111111111111111111111111111111111111111111111111 HUM: CCCTGTTCTTCATCGGGGAGCCCCAGGACTGGACGTGCCGCCTGCGCCAGCCGGCCTTTGGCATCAGC

BOV: TTCGTGCTCTGCATCTCGTGCATCCTGGTGAAAACCAATCGGTCCTCCTGGTGTTTGAGGCCAAGAT

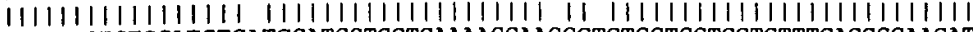

Ker: ThCG 11111111111111111111111111111111111111111111111111111111111111111 HUM: TTCGTGCTCTGCATCTCATGCATCCTGGTGAAAACCAACCGTGTCCTCCTGGTGTTTGAGGCCAAGAT

BOV: TCCCACCAGCTTCCACCGGAAGTGGTGGGGGCTCAACCTGCAGTTCCTGCTGGTCTTCCTCTGCACCT 11111111111111111111111111111111111111111111111111111111111111111 CCCCACCAGCTTCCACCGGAAGTGGTGGGGCTCAACCTGCAGTTCCTGCTGGTTTTCCTCTGCACCT



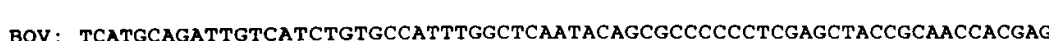

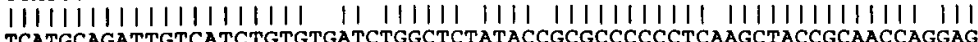
111111111111111111111111111111111111111111111111111111111111111111

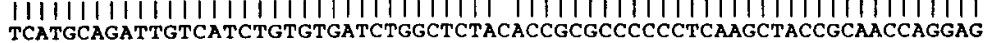

BOV: CTGgagGaCGagatCATCTTCATCACCTGCCACGAGGGCTCGCTCATGGCGCTGGGCTTCCTGATCGg

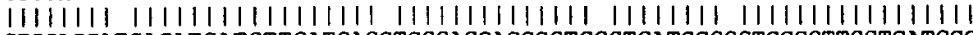
CTGGAGGATGAGATCATCTTCATCACGTGCCACGAGGGCTCCCTCATGGCCCTGGGCTTCCTGATCGG 11111111111111111111111111111111111111111111111111111111111111111 HUM: CTGGAGGATGAGATCATCTTCATCACGTGCCACGAGGGTCCCTCATGGCCCTGGGCTTCCTGATCGG

BOV: CTACACCTGCTTGCTGGCCGCCATCTGCTTCTTCTTCGCCTTCAAGTCCCGGAAGCTGCCAGAGAACT BOV: 1111111111111111111111111111111111111111111111111111111111111

RER: CTACACCTGCCTGCTGGCTGCCATCTGCTTCTTCTTTGCCTTCAAGTCCCGGAAGCTGCCAGAGAACT 11111111111111111111111111111111111111111111111111111111111111 HUM: CTACACCTGCCTG

BOV: TCAATGAAGCCAAGTTCATCACCTTCAGCATGCTCATCTTCTTCATCGTCTGGATCTCTTTCATCCCC 111111111111111111111111111111111111111111111111111111111111111

RER: TCAATGAAGCCAAGTTCATCACCTTCAGCATGCTCATCTTCTTCATCGTCTGGATCTCCTTCATTCCA

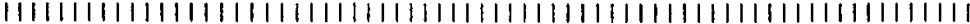

HUM: TCAATGAAGCCAAGTTCATCACCTTCAGCATGCTCATCTTCTTCATCGTCTGGATCTCCTTCATTCCA

BOV: GCCTACGCCAGCACTTACGGCAAGTTCGTCTCTGCCGTGGAGGTGATCGCCATCCTGGCGGCCAGCTT

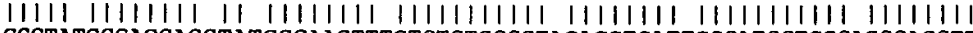

KER: GCCTATGCCAGCACCTATGGCAAGTTTGTCTCTGCCGTAGAGGTGATTGCCATCCTCGCAC IIIIIIII1111111111111111111111111111111111111111111111111111111111 HUM: GCCTATGCCAGCACCTATGGCAAGTTTGTCTCTGCCGTAGAGGTGATTGCCATCCTGGCAGCCAGCTI

BOV: TGGCTTGCTGGCCTGTATCTTCTTCAACAAGGTCTACATCATCCTCTTCAAGCCTTCCCGGAACACCA

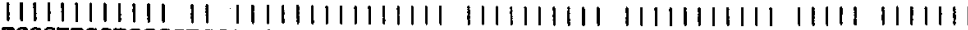
TGGCTTGCTGGCGTGCATCTTCTTCAACAAGATCTACATCATTCTCTTCAAGCCATCCCGCAACACCA 1111111111111111111111111111111111111111111111111111111111111111111111

HUM: TGGCTTGCTGGCGTGCATCTTCTTCAACAAGATCTACATCATTCTCTTCAAGCCATCCCGCAACACCA

BOV: TCGAGGAGgTGCGCTGCAGCACCGCGGCACACGCCTTCAAGgTGGCCGCCCGAGCCACGCTGCGCCGC TCGAGGagtgCGTtGCAGCACCGCAGCTCACGCTTTCAAGGTGGCTGCCCGGCCACGCTGCGCCGC 111111111111111111111111111111111111111111111111111111111111111 HUM: TCGAGGAGGTGCGTTGCAGCACCGCAGCTCACGCTTTCAAGGTGGCTGCCCGGGCCACGCTGCGCCGC

BOV: AGCAACGTCTCCCGCCAGCGGTCCAGCAGCCTAGGGGGCTCCACGGGATC I1 1111111111111111111111111111111111111111111

RER: AGCAACGTCTCCCGCAAGCGGTCCAGCAGCCTTGGGGGCTCCACGGGATC 111111111111111111111111111111111111111111111111 HUM: AGCAACGTCTCCCGCAAGCGGTCCAGCAGCCTTGGAGGCTCCACGGGATC
Figure 5. The sequence (798 bases) of the keratinocyte CaR cDNA obtained by RT-PCR aligned with the comparable regions of the bovine and human $\mathrm{CaR}$ cDNAs. The alignment begins at base number 1934 for the bovine sequence (numbered from the start of the coding region) and base number 1926 for the human sequence. in those cells, whereas the increase in uptake at $1.2 \mathrm{mM}$ Cao is best seen in keratinocytes grown in $1.2 \mathrm{mM}$ Cao and correlates with the increase in CaR mRNA seen in those cells.

The nonspecific cation channel of keratinocytes is a likely candidate to mediate the calcium-induced influx seen at 1.2 $\mathrm{mM}$ Cao because it is calcium activated and calcium permeable (20). Since previous studies had demonstrated the existence of this channel even in the early stages of keratinocyte differentiation (20), we tested the hypothesis that the increase in calcium influx with differentiation in $1.2 \mathrm{mM}$ Cao was due to increased opening time of this channel rather than to increased channel number. Since a major difference between cells grown in $0.07-0.15 \mathrm{mM}$ Cao and $1.2 \mathrm{mM}$ Cao is the extent of the rise in Cai (Fig. 1), we assessed the ability of Cai to regulate the opening of this channel. Representative recordings $(n=4$ for each condition) are shown in Fig. 8. At $50 \mathrm{nM}$ calcium, the channel is closed $80 \%$ of the time. A substantial increase in opening time (to $56 \%$ ) occurred at $500 \mathrm{nM}$ calcium, with no further increase at $70 \mu \mathrm{M}$ calcium. Thus, the increased capability of cells to accumulate calcium at $1.2 \mathrm{mM}$ Cao as they differentiate in the presence of calcium could reflect the greater opening time of their nonspecific cation channels as a result of their increase in Cai.

\section{Discussion}

Acutely increasing Cao to $0.1 \mathrm{mM}$ or above (calcium switch) leads to rapid changes in genomic and nongenomic events in keratinocytes, eventuating in terminal differentiation. Within minutes after the calcium switch, redistribution of desmoplakin 


\section{Ca $0.03 \quad 1.2 \quad \mathrm{mM}$}

\section{$\begin{array}{lllllllll}M & 1 & 2 & 3 & 4 & 1 & 2 & 3 & 4\end{array}$ \\ CaR들 ------- \\ GAPDH $\because----\cdots$}

1. PRECONFLUENT 3. 1 WK. POST

CONFLUENT

2. CONFLUENT

4. 2 WKS. POST

CONFLUENT

M. MARKER ( $\phi X$ 174/Hae III fragments)

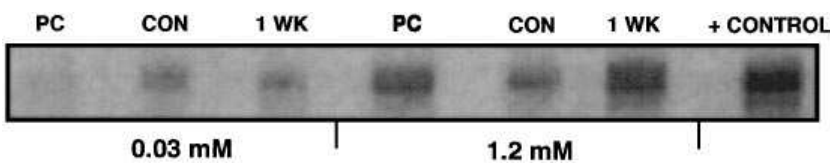

CaR mRNA levels

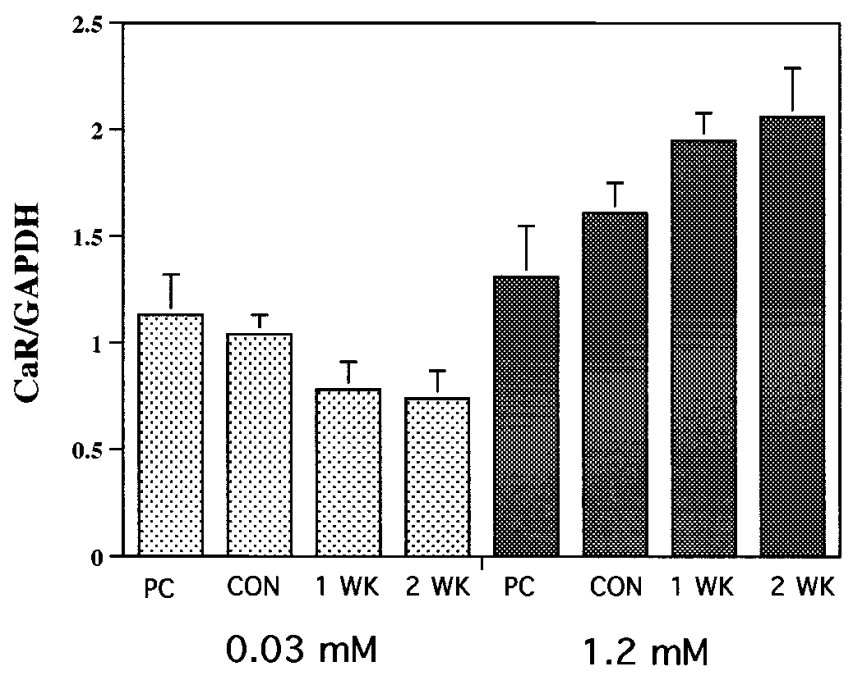

Figure 6. CaR mRNA levels as a function of differentiation. The keratinocytes were grown in KGM containing $0.09 \mathrm{mM}$ calcium for $2 \mathrm{~d}$ and then switched to 0.03 or $1.2 \mathrm{mM}$ calcium for an additional 3 (preconfluent), 5 (confluent), 12 ( $1 \mathrm{wk}$ postconfluent), or 19 ( 2 wk postconfluent) $d$ before harvest. The top panel shows the results using RT-PCR and contains the results for both $\mathrm{CaR}$ and GAPDH used to normalize the data. The middle panel shows the results using ribonuclease protection assay and includes a sample from bovine parathyroid tissue as a positive control (+CONTROL). PC, preconfluent cells; $C O N$, confluent cells; $1 \mathrm{WK}$, 1 -wk postconfluent cells. The results from three separate RT-PCR experiments were quantitated by densitometry and expressed as a ratio of CaR/GAPDH mRNA, as shown in the bottom panel (error bars include mean $\pm \mathrm{SD}$ ).

occurs from cytosol to membranes, where it participates in desmosome formation $(3,4)$. Within hours of the calcium switch, levels of involucrin and loricrin (precursors of the CE) and keratinocyte-specific transglutaminase (the enzyme that cross-links protein precursors into the CE) increase $(35,36)$. Within 1-2 d of the calcium switch, CE formation is apparent (22).
A

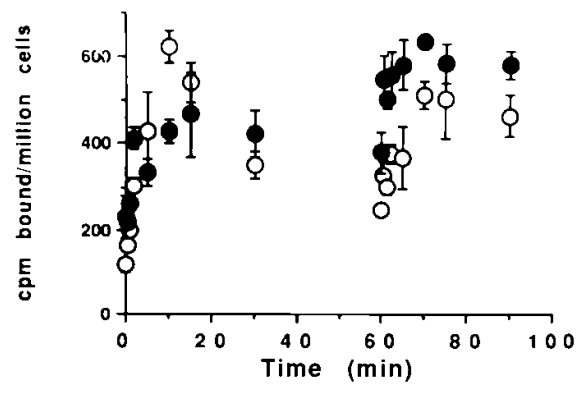

B

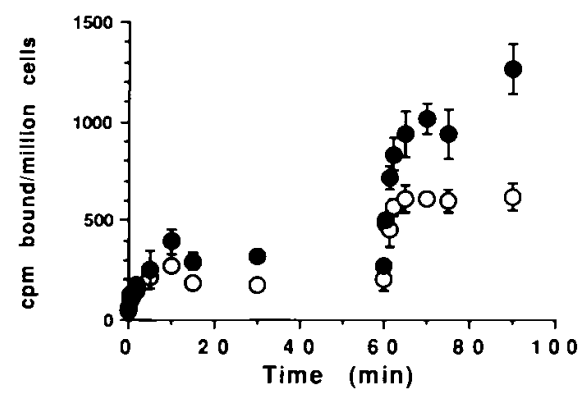

C

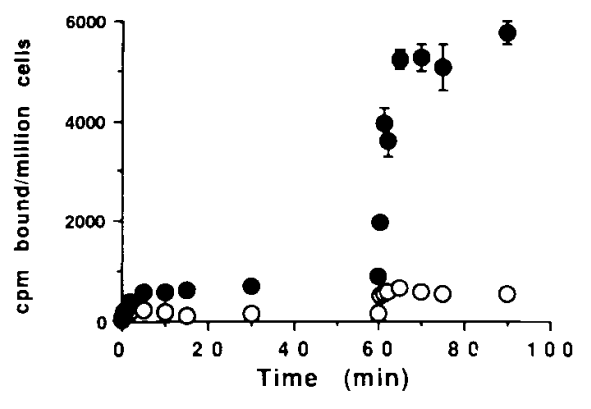

Figure 7. ${ }^{45} \mathrm{Ca}$ influx of keratinocytes grown in $0.07 \mathrm{Cao}(\mathrm{O})$ or 1.2 mM Cao $(\bullet)$ to $80 \%$ confluence $(A), 100 \%$ confluence $(B)$, or $1 \mathrm{wk}$ after confluence $(C)$. Keratinocytes in 12-well multiwell plates were equilibrated with buffer A containing no Cao for $10 \mathrm{~min}$ before incubating with $20,000 \mathrm{cpm}{ }^{45} \mathrm{Ca} / \mathrm{ml}$ buffer A containing $0.03 \mathrm{mM}$ Cao for various lengths of time. At $60 \mathrm{~min}$, the medium was quickly changed to one containing $1.2 \mathrm{mM} \mathrm{Cao}$ and $800,000 \mathrm{cpm}{ }^{45} \mathrm{Ca} / \mathrm{ml}$ of buffer A to increase the Cao without altering the specific activity of ${ }^{45} \mathrm{Ca}$ throughout the 90-min period of the experiment. The amount of ${ }^{45} \mathrm{Ca}$ associated with the cells was determined at different time points by scintillation spectroscopy after washing the cells with 5 mM EGTA. Data are expressed as the mean $\pm \mathrm{SD}$ of triplicate determinations.

Despite a wealth of knowledge about the events that occur with the calcium switch in keratinocytes, the mechanism by which keratinocytes respond to changes in Cao is not well understood. One of the earliest responses of human keratinocytes to increases in Cao is an acute increase in Cai. Stepwise addition of Cao to neonatal human keratinocytes is followed by a progressive increase in Cai, where the initial spike of increased Cai is followed by a prolonged plateau of higher Cai (7). This response of Cai to Cao in keratinocytes is saturated at $2.0 \mathrm{mM} \mathrm{Cao}(7,8)$.

The Cai response of keratinocytes to Cao resembles the Cai response of parathyroid cells to Cao $(24,25,37-39)$, in that 


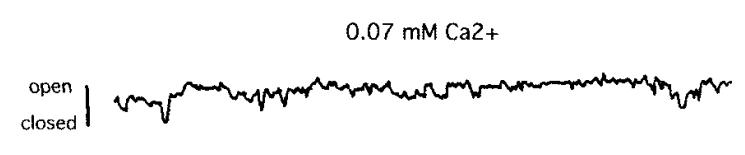

$500 \mathrm{nM} \mathrm{Ca2+}$
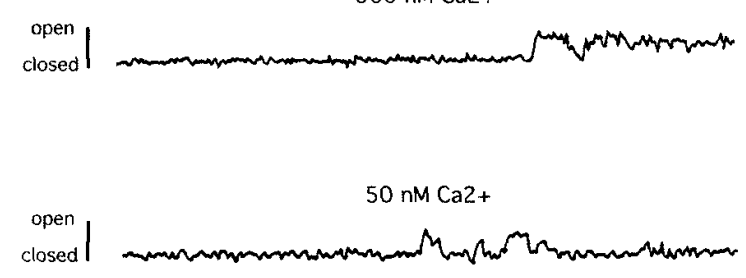

$1.0 \mathrm{pA}$

$$
10.00 \mathrm{~ms}
$$

Figure 8. Activation of the nonspecific cation channel by calcium. Currents were recorded from a membrane patch in the excised inside-out configuration, with the cytoplasmic side of the plasma membrane exposed to differing concentrations of calcium. Normal human keratinocytes were plated on plastic dishes in KGM Ringer containing $50 \mathrm{nM}$ calcium ( $2 \mathrm{mM}$ EGTA, $0.92 \mathrm{mM} \mathrm{CaCl}_{2}$ ). After recording membrane currents at this calcium concentration, the bath solution was switched to $500 \mathrm{nM}$ calcium ( $2 \mathrm{mM} \mathrm{EGTA,} 1.78 \mathrm{mM} \mathrm{CaCl}_{2}$ ), then to $0.07 \mathrm{mM}$ calcium. The pipette contained KGM Ringer with 0.07 $\mathrm{mM}$ calcium throughout the experiment. These results are representative of four recordings at each Cai. Increasing the Cai from 50 to $500 \mathrm{nM}$ increased the probability of the channel being open from 20 to $56 \%$.

a rapid and transient increase in Cai is followed by a sustained increase in Cai above the basal level. This multiphasic response is attributed to an initial release of calcium from intracellular stores followed by an increased influx of calcium through voltage-independent cation channels. The parathyroid cell contains a cell membrane CaR thought to mediate this response to Cao. This receptor can activate the PLC pathway, leading to an increase in $\mathrm{IP}_{3}$ levels as well as stimulating calcium influx and chloride currents $(25,26,39)$. As in keratinocytes, the response of Cai to Cao in parathyroid cells is saturated at $2.0-2.5 \mathrm{mM}$ Cao. The $\mathrm{CaR}$ in the parathyroid cell is not highly selective in that it shows a Cai response to other divalent cations, such as barium, strontium, and magnesium, and to trivalent cations such as lanthanum and gadolinium. (37). In this study we have shown very similar characteristics in the calcium response of keratinocytes. In particular, we have shown calcium-activated calcium influx and demonstrated that barium and strontium as well as calcium can raise Cai and activate chloride currents, although some of the apparent increase in Cai in response to these ions may be due to their ability to enter the cell and interact with Fura-2 (40). Other investigators have demonstrated calcium-activated $\mathrm{IP}_{3}$ production (13-17) and non-calcium cation-stimulated influx (18) in keratinocytes. Most importantly, however, we have shown that the mRNA for a CaR nearly identical to that reported in the parathyroid gland $(26,34)$ is found in keratinocytes. The mRNA levels of the $\mathrm{CaR}$ change with differentiation in a manner that correlates with the changes in the calcium response during differentiation.

At least two mechanisms appear to underlie the Cai re- sponse of the keratinocyte to Cao: release of Cai from intracellular stores and calcium influx through nonspecific cation channels. With differentiation, the basal Cai rises, the acute and transient response of Cai to Cao is lost, and calcium-activated calcium influx increases. The CaR may participate in both mechanisms, but its role may be influenced by the basal Cai. In cells grown in low calcium conditions, the mRNA for the $\mathrm{CaR}$ is low and tends to decrease with time in culture, explaining the loss of the acute Cai response to Cao if, as seems likely, the $\mathrm{CaR}$ in the keratinocyte is coupled to the PLC pathway in the same fashion as that in the parathyroid cell. Transformed keratinocytes, which do not differentiate under the influence of calcium, maintain a robust acute Cai response to Cao, not losing this response with time in culture, unlike normal keratinocytes (21). Furthermore, transformed keratinocytes do not lose their mRNA for the CaR when grown in low calcium conditions (Ratnam, A., and D.D. Bikle, unpublished observations). However, normal keratinocytes grown in higher Cao lose this acute Cai response to Cao as they differentiate but do not lose their mRNA for CaR; rather, their CaR mRNA levels increase. Associated with this rise in $\mathrm{CaR}$ is an increase in calcium-activated calcium influx. This also might be coupled to the $\mathrm{CaR}$, either directly or via a rise in basal Cai. The rise in basal Cai could alter these processes by two mechanisms. First, it could decouple the CaR from direct activation of the PLC pathway (by activating this pathway directly), accounting for loss of the acute Cai response to Cao. Second, it could activate the nonspecific cation channels as shown in this report, leading to the marked increase in calcium-activated calcium influx seen in the differentiated cells.

From these studies, we conclude that the calcium-sensing mechanism of keratinocytes involves a CaR linked to the acute but transient elevation of Cai via activation of the PLC pathway as well as to calcium-activated calcium influx through nonspecific cation channels, which leads to a more sustained increase in Cai. The sustained rise in Cai appears to be more important for differentiation $(8-12,23,31)$, but the acute rise in Cai may signal the mechanisms required for the sustained increase in Cai. The exact means by which the CaR is linked to both mechanisms and the manner in which $\mathrm{CaR}$ production and function are controlled during differentiation remain subjects for future investigation.

\section{Acknowledgments}

This work was supported by grants from the Veterans Administration and the National Institutes of Health (AR 38386 and AR 39448).

\section{References}

1. Secuin, N.B., J.F. Cullard, C. Kerai, F. Bernard, A. Watrin, J. Demaille, and J.J. Guihou. 1990. Reconstituted skin in culture: a simple method with optimal differentiation. Differentiation. 44:232-238.

2. Watt, F. 1988. An experimental model for studying how proliferation and terminal differentiation are coordinated in the epidermis. J. Cell Sci. 90: $525-529$.

3. Hennings, H., D. Michael, C. Cheng, P. Steinert, K. Holbrook, and S.H. Yuspa. 1980. Calcium regulation of growth and differentiation of mouse epidermal cells in culture. Cell. 19:245-254.

4. Hennings, H., and K.A. Holbrook. 1983. Calcium regulation of cell-cell contact and differentiation of epidermal cells in culture. Exp. Cell Res. 143:127142.

5. Eckert, R.L. 1989. Structure, function, and differentiation of the keratinocyte. Physiol. Rev. 69:1316-1346.

6. Hennings, H., F.H. Kruszewski, S.H. Yuspa, and R.W. Tucker. 1989. In- 
tracellular calcium alterations in response to increased calcium in normal and neoplastic keratinocytes. Carcinogenesis (Oxf.). 10:777-780.

7. Pillai, S., and D.D. Bikle. 1991. Role of intracellular-free calcium in the cornified envelope formation of keratinocytes: differences in the mode of action of extracellular calcium and 1,25 dihydroxyvitamin $\mathrm{D}_{3}$. J. Cell Physiol. 146: 94-100.

8. Sharpe, G.R., J.I. Gillespie, and J.R. Greenwell. 1989. An increase in intracellular free calcium is an early event during differentiation of cultured human keratinocytes. FEBS Lett. 254:25-28.

9. Kruszewski, F.H., H. Hennings, R.W. Tucker, and S.H. Yuspa. 1991. Differences in the regulation of intracellular calcium in normal and neoplastic keratinocytes are not caused by ras gene mutations. Cancer Res. 51:4206-4212.

10. Kruszewski, F.H., H. Hennings, S.H. Yuspa, and R.W. Tucker. 1991. Regulation of intracellular free calcium in normal murine keratinocytes. Am. J. Physiol. 261:C767-C773.

11. Yuspa, S.H., A.E. Kilkenny, P.M. Steinert, and D.R. Roop. 1989. Expression of murine epidermal differentiation markers is regulated by restricted extracellular calcium concentrations in vitro. J. Cell Biol. 109:1207-1217.

12. Pillai, S., and D.D. Bikle. 1992. Lanthanum influx into cultured human keratinocytes: effect on calcium flux and terminal differentiation. J. Cell. Physiol. 151:623-629.

13. Jaken, S., and S.H. Yuspa. 1988. Early signs for keratinocyte differentiation: role of $\mathrm{Ca}^{2+}$-mediated inositol lipid metabolism in normal and neoplastic epidermal cells. Carcinogenesis (Oxf.). 9:1033-1038.

14. Tang, W., V.A. Ziboh, R. Isseroff, and D. Martiniez. 1988. Turnover of inositol phospholipids in cultured murine keratinocytes: possible involvement of inositol triphosphate in cellular differentiation. J. Invest. Dermatol. 90:37-43.

15. Talwar, H.S., G.J. Fisher, V.A. Harris, and J.J. Voorhees. 1989. Agonistinduced hydrolysis of phosphoinositides and formation of 1,2-diacylglycerol in adult human keratinocytes. J. Invest. Dermatol. 93:241-245.

16. Lee, E., and S.H. Yuspa. 1991. Aluminum fluoride stimulates inositol phosphate metabolism and inhibits expression of differentiation markers in mouse keratinocytes. J. Cell. Physiol. 148:106-115.

17. Moscat, J., T.P. Flemming, C.J. Molloy, M. Lopez-Barahona, and S.A. Aaronson. 1989. The calcium signal for Balb 1 MK keratinocyte terminal differentiation induces sustained alterations in phosphoinositide metabolism without detectable protein kinase C activation. J. Biol. Chem. 264:11228-11235.

18. Reiss, M., L. Lipsey, and Z.-L. Zhou. 1991. Extracellular calciumdependent regulation of transmembrane calcium fluxes in murine keratinocytes. J. Cell. Physiol. 147:281-291.

19. Mauro, T.M., P.A. Pappone, and R. Rivkah Isseroff. 1990. Extracellular calcium affects the membrane currents of cultured human keratinocytes. J. Cell. Physiol. 143:13-20.

20. Mauro, T.M., R. Rivkah Isseroff, R. Lasarow, and P.A. Pappone. 1993. Ion channels are linked to differentiation in keratinocytes. J. Membr. Biol. 132: 201-209.

21. Pillai, S., D.D. Bikle, M.L. Mancianti, and M. Hincenbergs. 1991. Uncoupling of the calcium-sensing mechanism and differentiation in squamous carcinoma cell lines. Exp. Cell Res. 192:567-573.

22. Pillai, S., D.D. Bikle, M.L. Mancianti, P. Cline, and M. Hincenbergs. 1990. Calcium regulation of growth and differentiation of normal human keratinocytes: modulation of differentiation competence by growth and extracellular calcium. J. Cell. Physiol. 143:294-302.

23. Pillai, S., and D.D. Bikle. 1992. ATP stimulates phosphoinositide metabolism, mobilizes intracellular calcium and inhibits terminal differentiation of human epidermal keratinocytes. J. Clin. Invest. 90:42-51.
24. Nemeth, E.F. 1990. Regulation of cytosolic calcium by extracellular divalent cations in C-cells and parathyroid cells. Cell Calcium. 11:323-327.

25. Brown, E.M., C.J. Chen, O. Kifor, M.S. Leboff, G. El-Hajj, V. Fajtova, and L.T. Rubin. 1990. $\mathrm{Ca}^{2+}$-sensing, second messengers, and the control of parathyroid hormone secretion. Cell Calcium. 11:333-337.

26. Brown, E.M., G. Gamba, D. Riccardi, M. Lombardi, R. Butters, O. Kifor, A. Sun, M.A. Hediger, J. Lytton, and S.C. Hebert. 1993. Cloning and characterization of an extracellular $\mathrm{Ca}^{2+}$-sensing receptor from bovine parathyroid Nature (Lond.). 366:575-580.

27. Pillai, S., D.D. Bikle, M. Hincenbergs, and P.M. Elias. 1988. Biochemical and morphological characterization of growth and differentiation of normal human neonatal keratinocytes in a serum-free medium. J. Cell. Physiol. 134: 229-237.

28. Grynkiewicz, G., M. Poenie, and R.Y. Tsien. 1985. A new generation of calcium indicators with greatly improved fluorescence properties. J. Biol. Chem. 260:3440-3447.

29. Horn, R., and A. Marty. 1988. Muscarinic activation of ionic currents measured by a new whole cell recording method. J. Gen. Physiol. 92:145-159.

30. Armstrong, C.M., and F. Bezanilla. 1974. Charge movement associated with the opening and closing of the activation gates of the Na channels. J. Gen. Physiol. 63:533-552.

31. Chomczynski, P., and N. Sacchi. 1987. Single-step method of RNA isolation by acid guanidinium thiocyanate-phenol-chloroform extraction. Anal. Biochem. 162:156-159.

32. Pollak, M.R., E.M. Brown, Y.-H. Wu Chou, S.C. Hebert, S.J. Marx, B. Steinmann, T. Levi, C.E. Seidman, and J.G. Seidman. 1993. Mutations in the human $\mathrm{Ca}^{2+}$-sensing receptor gene cause familial hypocalciuric hypercalcemia and neonatal severe hyperparathyroidism. Cell. 75:1297-1303.

33. Bikle, D.D., J. Harris, B.P. Halloran, C.T. Roberts, Jr., D. LeRoth, and E. Morey-Holton. 1994. Expression of the genes for the insulin like growth factors and their receptors in bone during skeletal growth. Am. J. Physiol. 267: 278-286.

34. Garrett, J.E., I.V. Capuano, L.G. Hammerland, B.C.P. Hung, E.M. Brown, S.C. Hebert, E.F. Nemeth, and F. Fuller. 1995. Molecular cloning and functional expression of human parathyroid calcium receptor cDNAs. J. Biol. Chem. 270:12919-12925.

35. Rice, R.H., and H. Green. 1979. Presence in human epidermal cells of a soluble protein precursor of the cross-linked envelope: activation of the crosslinking by ions. Cell. 18:681-694.

36. Hohl, D., U. Lichti, D. Breitkreutz, P.M. Steinert, and D.R. Roop. 1991. Transcription of the human loricrin gene in vitro is induced by calcium and cell density and suppressed by retinoic acid. J. Invest. Dermatol. 96:414-418.

37. Nemeth, E.F., and A. Scarpa. 1987. Rapid mobilization of cellular calcium in bovine parathyroid cells evoked by extracellular divalent cations. $J$. Biol. Chem. 262:5188-5196.

38. Muff, R., E.F. Nemeth, S. Haller-Brem, and J.A. Fischer. 1988. Regulation of hormone secretion and cytosolic calcium by calcium in parathyroid cells and C-cells: role of voltage sensitive calcium channels. Arch. Biochem. Biophys. 265:128-135.

39. Shoback, D.M., L.A. Membreno, and J.G. McGhee. 1988. High calcium and other divalent cations increase inositol trisphosphate in bovine parathyroid cells. Endocrinology. 123:382-389.

40. Li, L., F.H. Kruszewski, K. Punnonen, R.W. Tucker, S.H. Yuspa, and H. Hennings. 1993. Strontium induces murine keratinocyte differentiation in vitro in the presence of serum and calcium. J. Cell. Physiol. 154:643-653. 